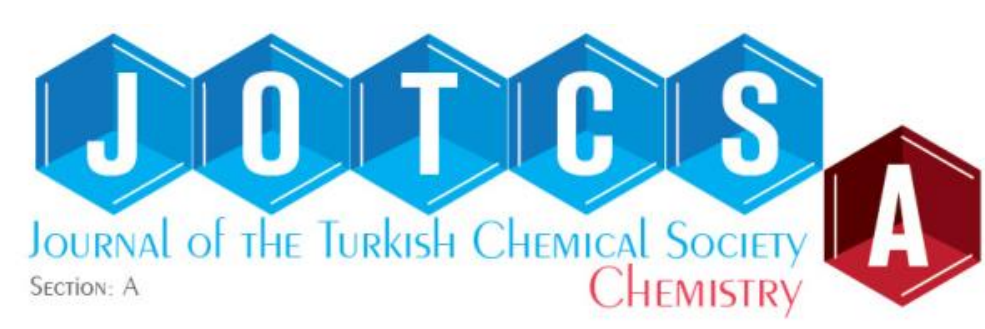

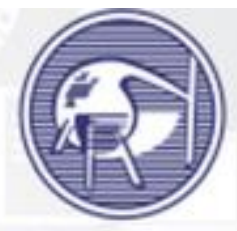

TURKISH

CHEMICAL SOCIETY

\title{
The Uranium Recovery from Aqueous Solutions Using Amidoxime Modified Cellulose Derivatives. II. Uranium Uptake Behavior of Amidoximated Ethyl Cellulose
}

\author{
Seyhan Şener Başarır, Nursel Pekel Bayramgil $\mathbb{D}$ * \\ Hacettepe University, Faculty of Science, Chemistry Department, 06800, Beytepe, Ankara, \\ Turkey
}

\begin{abstract}
Amidoxime modified ethyl cellulose (EC- $g-A O)$ was utilized to recover uranyl ions from aqueous solutions through a process of complexation. Adsorption trials were carried out at varying $\mathrm{UO}_{2}{ }^{2+}$ concentrations ranging from 100 to $1000 \mathrm{mg} / \mathrm{L}$ and at temperatures ranging from 25 to $50^{\circ} \mathrm{C}$. Thermodynamics and kinetics of the adsorption of uranyl ions $\left(\mathrm{UO}_{2}{ }^{2+}\right)$ by EC- $g$-AO were examined. The findings suggested an adsorption capacity of $240 \mathrm{mg} \mathrm{UO}_{2}{ }^{2+} / \mathrm{g}$ dry copolymer. Thermodynamic parameters applicable to the interaction of $\mathrm{UO}_{2}{ }^{2+}$ with $\mathrm{EC}-g-\mathrm{AO}$ were calculated from thermodynamic relations. Calculations indicated that adsorption took place through powerful electrostatic interactions with an enthalpy of $-23.6 \mathrm{~kJ} / \mathrm{mol}$. $\mathrm{UO}_{2}{ }^{2+}$ desorption was investigated by desorption agents like EDTA, $\mathrm{HCl}, \mathrm{NaHCO}_{3}$, and $\mathrm{NaOH}$. The desorption yield found for $\mathrm{NaHCO}_{3}$ was $52 \%$.
\end{abstract}

Keywords: Ethyl cellulose, uranium, $\mathrm{NaHCO}_{3}$, adsorption enthalpy, EDX.

Submitted: May 08, 2017. Accepted: March 13, 2018.

Cite this: Şener Başarır S, Pekel Bayramgil N. The Uranium Recovery from Aqueous Solutions Using Amidoxime Modified Cellulose Derivatives. II. Uranium Uptake Behavior of Amidoximated Ethyl Cellulose. JOTCSA. 2018;5(2):521-38.

DOI: http://dx.doi.org/10.18596/jotcsa.310947.

*Corresponding author. E-mail: nursel@hacettepe.edu.tr. Phone \& Fax: 90 (312) 2977965. 


\section{INTRODUCTION}

Seawater contains abundant dissolved alkali and rare earth alkali metal ions, alongside a lesser amount of some valuable metals like lithium and uranium (1). The relevant literature (2-5) features numerous studies related to the removal of heavy metal ions from seawater and wastewater, especially for the selective recovery and the enrichment of uranyl ions.

Being toxic and radioactive, uranium poses a risk for both surface and underground waters. On the other hand, uranium is utilized as a raw material for nuclear power plants and has had a tremendous commercial significance. Nevertheless, as the uranium reserves are anticipated to be depleted in the near future, studies have focused on the recovery of uranium from natural water sources $\left(0.1-10 \mathrm{mg} \mathrm{U} / \mathrm{m}^{3}\right)$, especially from sea water $\left(2.8-3.3 \mathrm{mg} \mathrm{U} / \mathrm{m}^{3}\right)$. Various organic adsorbents containing different functional groups or organic chelates that are more or less selective towards uranium were synthesized and used to recover uranium from seawater or mining wastewaters (6-9). The desired properties of these chelates are high capacity, high selectivity, fast kinetics, high mechanical strength, and a fast equilibrium established with metal ion solution. Notably, amidoxime containing synthetic and natural polymers are the most promising systems for the uranium recovery (10). From past to present, a number of studies were published on the adsorption of uranyl ions by polymers and copolymers containing amidoxime functional groups (11-14).

Neti et al. (15) reported their effort to induce hydrophilicity in the support polymer through the grafting of a hydrophilic monomer onto PE prior to ATRP polymerization of acrylonitrile and 2hydroxyethyl acrylate. The prepared adsorbents demonstrated promise $(159.9 \mathrm{~g} \mathrm{U} / \mathrm{kg}$ of adsorbent) in laboratory screening tests using a high uranium concentration brine and $1.24 \mathrm{~g}$ $\mathrm{U} / \mathrm{kg}$ of adsorbent in the filtered natural seawater in 21 days. Abney et al. (16) published a review of inorganic and organic materials used in the recovery of uranium from seawater and their detailed synthesis methods. He mentioned that amidoxime-functionalized polymers are the most technologically ripe adsorbent for the uranium recovery and have indicated impressive performance following protracted contact with seawater in screening studies, as well as in longterm dehiscence at the pilot scale in the open ocean. In another study (17), uranyl ion uptake from sulfuric acid solutions has been evaluated as a function of $\mathrm{pH}$ and sulfate concentration, with comparison to a commercially available weak base anion exchange resin. Maximum uranyl loading capacity was found as $269.50 \mathrm{mg} / \mathrm{g}$ for weak base anion exchange resin.

It is well known that currently available adsorbents require security measures and a sophisticated installation process, and they are more expensive than water treatment. Due to such constraints and environmental issues, there is a growing interest in the use of biomass for the removal of dissolved metals. For this purpose, numerous low-cost biomasses have been developed and commercially utilized to control pollution (18-21). Examples to low-cost 
adsorbents include activated carbon, clay, agricultural waste, tea leaves, cellulose, fly ash, wool fiber, animal bones, immobilized fungal biomass, peanut shell pellets, and pineapple shells. Among them, cellulose has attractive properties; it is biodegradable, biocompatible, highly abundant, cheap, and it has been obtained from renewable resources. Cellulose interacts with soil microorganisms, transforms into eco-friendly end products, $\mathrm{CO}_{2}$ and $\mathrm{H}_{2} \mathrm{O}$, and does not cause secondary pollution; thus, it is superior to synthetic polymers $(22,23)$.

In our previous study, we synthesized graft copolymers consisting of ethyl cellulose (EC) and acrylonitrile (AN) through high-energy radiation. Details concerning the characterization and yield of grafting and amidoxime conversion were provided in this previous study (24). This study aimed to investigate how $\mathrm{UO}_{2}{ }^{2+}$ - and amidoxime-modified ethyl cellulose interacted within a certain temperature range, and it also revealed some conclusions about the physicochemical quantities that are effective in the specific adsorption process. These interactions were investigated as a function of temperature based on adsorption isotherms. The enthalpy, entropy, activation energy, and Gibbs free energy parameters of $\mathrm{UO}_{2}{ }^{2+}$ adsorption were calculated from basic thermodynamic equations. Different releasing agents including $\mathrm{HCl}, \mathrm{EDTA}, \mathrm{NaHCO}_{3}$ and $\mathrm{NaOH}$ were tested for desorption studies. Morphological, structural, and thermal changes were monitored through SEM-EDX, FTIR/ATR, and TGA, respectively.

\section{MATERIALS AND METHODS}

\section{Materials}

Ethyl cellulose (Sigma-Aldrich Chemie GmbH, Germany) and acrylonitrile (Aldrich, Germany) were used as received. Hydroxylamine hydrochloride and sodium hydroxide were supplied from Riedel de Haën and Merck, respectively.

Uranyl nitrate, $\mathrm{UO}_{2}\left(\mathrm{NO}_{3}\right)_{2} .6 \mathrm{H}_{2} \mathrm{O}$ (purity $\geq 98 \%$ ) ( $\mathrm{BDH}$ Chemicals Ltd., Poole, U.K.) was utilized as the source of uranyl ions. Sodium salicylate, $\mathrm{HOC}_{6} \mathrm{H}_{4} \mathrm{COONa}$ (analytical grade), which forms a complex with $\mathrm{UO}_{2}{ }^{2+}$ for UV spectrophotometric measurements, was obtained from Fischer Scientific, U.K.

\section{Synthesis of ethyl cellulose and acrylonitrile graft copolymers}

Ethyl cellulose (EC) and acrylonitrile (AN) graft copolymers (EC-g-AN) were synthesized by irradiating various initial feed compositions of EC and $\mathrm{AN}$ through ${ }^{60} \mathrm{Co}-\gamma$ irradiator at room temperature. The conversion of initial mixtures into crosslinked, insoluble structures was determined gravimetrically after the copolymers kept in dimethyl formamide for a period of one week in order to extract the unreacted monomers and uncrosslinked soluble fractions. With $100 \%$ success, nitrile groups were converted into amidoxime groups in a neutralized $\mathrm{NH}_{2} \mathrm{OH} . \mathrm{HCl}$ solution at $50{ }^{\circ} \mathrm{C}$. The details concerning the characterization, radiation synthesis, and amidoximation of EC- $g$-AN copolymers were reported in our previous study (24). 


\section{Adsorption of $\mathrm{UO}_{2}{ }^{2+}$ onto amidoxime (AO) modified ethyl cellulose (EC-g-AO)}

Approximately $0.25 \mathrm{~g}$ of EC-g-AO copolymers in cylindrical form ( $\sim 0.5 \mathrm{~cm}$ in length) were immersed into $25 \mathrm{~mL} \mathrm{UO}_{2}{ }^{2+}$ solutions at concentrations varying from 100 to $1000 \mathrm{mg} / \mathrm{L}(\mathrm{pH} \mathrm{4.1)}$. In a thermostatically controlled water bath, the solutions were shaken in closed flasks at $25^{\circ} \mathrm{C}$ $\pm 0.5{ }^{\circ} \mathrm{C}$. $0.5 \mathrm{~mL}$ aliquot was taken and sodium salicylate was added to form a complex during the shaking process. Then, the absorbance of this solution was recorded at $429 \mathrm{~nm}$ using a Jasco V-530 model UV-vis spectrophotometer and concentration changes were read from a previously obtained calibration curve. The adsorption equilibrium was achieved in 7-10 days. We repeated the adsorption trials following the same experimental route at other temperatures $\left(30^{\circ} \mathrm{C}, 40^{\circ} \mathrm{C}\right.$, and $50^{\circ} \mathrm{C}$ ). The adsorbed amount of $\mathrm{UO}_{2}{ }^{2+}$ was calculated with the equation (1):

$$
q_{e}=\frac{V}{m} x\left(C_{0}-C\right)
$$

Where $q_{e}$ is the amount of adsorbed $\mathrm{UO}_{2}{ }^{2+}\left(\mathrm{mg} \mathrm{UO}_{2}{ }^{2+} / \mathrm{g}\right.$ dry EC- $\left.\mathrm{E}-\mathrm{AO}\right), \mathrm{V}$ is the volume of the $\mathrm{UO}_{2}{ }^{2+}$ solution $(\mathrm{L}), \mathrm{m}$ is the dry weight of $\mathrm{EC}-\mathrm{g}-\mathrm{AO}(\mathrm{g})$, and $\mathrm{C}_{0}$ and $\mathrm{C}$ are the initial and equilibrium concentrations of $\mathrm{UO}_{2}{ }^{2+}(\mathrm{mg} / \mathrm{L})$, respectively.

The kinetics and thermodynamic quantities as activation energy $\left(E_{a}\right)$, adsorption enthalpy $\left(\Delta \mathrm{H}^{\circ}\right.$ ads), Gibbs free energy of adsorption ( $\Delta \mathrm{G}^{\circ}{ }^{a d s}$ ), and entropy of adsorption ( $\Delta \mathrm{S}^{\circ}$ ads) were calculated based on the below-given classical equations, respectively:

$$
\begin{array}{rr}
k=A \cdot e^{-\frac{E a}{R T}} & \text { Arrhenius equation } \quad \text { (Eq. 2) } \\
\Delta G_{a d s}^{0}=-R T \ln K_{L} & \text { Gibbs free energy (Eq. 3) } \\
\ln K_{L}=-\Delta H^{0} / R T+\Delta S^{0} / R & \text { Gibbs-Helmholtz equation (Eq. 4) }
\end{array}
$$

\section{Desorption of $\mathrm{UO}_{2}{ }^{2+}$ from EC-g-AO copolymers using different agents}

Solutions each of which having the concentration of $0.1 \mathrm{M} E D T A, \mathrm{NaOH}, \mathrm{HCl}$, and $\mathrm{NaHCO}_{3}$ functioned as desorption agents in order to release adsorbed $\mathrm{UO}_{2}{ }^{2+}$ from EC- $g$-AO copolymers. EDTA was provided by $\mathrm{BDH}$; and the other three were obtained from Merck, Darmstadt, Germany. Also, desorption was carried out at $\mathrm{pH} 4.1$. $\mathrm{UO}_{2}{ }^{2+}$ adsorbed $\mathrm{EC}-\mathrm{g}-\mathrm{AO}$ copolymers were placed, separately and in predetermined amounts, into the aforementioned solutions, and the concentration of released $\mathrm{UO}_{2}{ }^{2+}$ was measured in regular intervals with the UV-Vis spectrophotometer at $429 \mathrm{~nm}$. Desorption (\%) values were calculated in the following manner:

$$
\text { Desorption }(\%)=\frac{\text { amount of released } \mathrm{UO}_{2}^{2+}}{\text { total amount of adsorbed } \mathrm{UO}_{2}^{2+}} \times 100
$$

\section{Thermal, spectroscopic, and morphological analyses of $\mathrm{UO}_{2}{ }^{2+}$ adsorbed EC-g-AO}

We directly recorded the FTIR/ATR spectra of EC-g-AO copolymers with and without $\mathrm{UO}_{2}{ }^{2+}$ in a $4000-400 \mathrm{~cm}^{-1}$ range and took a total of 10 scans at $4 \mathrm{~cm}^{-1}$ resolution. A Nicolet IS10 Model FTIR/ATR spectrometer was used for this operation. We examined $\mathrm{UO}_{2}{ }^{2+}$ adsorbed EC-g-AO's 
thermal behavior with a DTG-60H Shimadzu (Simultaneous DTA-TG Apparatus) thermogravimetric analyzer in $\mathrm{N}_{2}$ atmosphere; the temperature range was $0-700{ }^{\circ} \mathrm{C}$ and the heating rate was $10^{\circ} \mathrm{C} / \mathrm{min}$. The flow rate of $\mathrm{N}_{2}$ gas was $60 \mathrm{~mL} / \mathrm{min}$. SEM images of $\mathrm{UO}_{2}{ }^{2+}$ adsorbed EC- $g$-AO copolymers were obtained with Quanta 200 FEG SEM-FEI Model Scanning Electron Microscope, which enabled an observation of morphological changes at an accelerating voltage ranging from $10.00 \mathrm{kV}$ to $15.00 \mathrm{kV}$. We ensured the conductivity of polymer samples by gold-coating. A simultaneous analysis of SEM and EDX (Energy Dispersive X-Ray Spectroscopy) with Bruker Electron Microscope enabled the elemental analysis of $\mathrm{UO}_{2}{ }^{2+}$ adsorbed EC-g-AO copolymers.

\section{RESULTS AND DISCUSSION}

Detailed information regarding the amidoxime conversion, radiation synthesis, and characterization of EC-g-AO copolymers were presented as another study (24). EC-g-AO copolymers were subjected to adsorption experiments in order to determine their $\mathrm{UO}_{2}{ }^{2+}$ uptake capacity, which is explained in the experimental section. For the adsorption kinetics studies, copolymer samples were removed from $\mathrm{UO}_{2}{ }^{2+}$ solutions at regular intervals and complexed with sodium salicylate. Then, using a UV-Vis spectrophotometer, the absorbance of orange-colored complexes was recorded at $429 \mathrm{~nm}$.

The ion-exchange mechanism for $\mathrm{UO}_{2}{ }^{2+}$, which binds to the polymer, is complicated by the hydrolyzation of $\mathrm{UO}_{2}{ }^{2+}$ in an aqueous solution within the $\mathrm{pH}$ range of the examined adsorption system, and different types of hydrolyzed $\mathrm{UO}_{2}{ }^{2+}$ species are formed. $\mathrm{UO}_{2}{ }^{2+}$ species are dominant in $\mathrm{pH}$ 1-4 range. At $\mathrm{pH} 4$, the presence of $\mathrm{UO}_{2}(\mathrm{OH})^{+}$within the solution remains around $2.2 \%$; the maximum value of which rises to $18.6 \%$ at $\mathrm{pH}$ 6. The presence of $\mathrm{UO}_{2}(\mathrm{OH})_{2}$ within the solution - maintained at $\mathrm{pH} 4-$ is approximately $1.5 \%$. $\mathrm{UO}_{2}{ }^{2+}$ and $\mathrm{H}_{3} \mathrm{O}^{+}$compete in the solution within the range of $\mathrm{pH} 1-4$. As the aqueous solution's $\mathrm{pH}$ value rises from 1 to $4, \mathrm{UO}_{2}{ }^{2+}$ adsorption increases, whereas the adsorption of $\mathrm{H}_{3} \mathrm{O}^{+}$decreases. Above $\mathrm{pH} 4$, the hydrolysis of $\mathrm{UO}_{2}{ }^{2+}$ triggers the formation of $\mathrm{UO}_{2}(\mathrm{OH})_{2}, \mathrm{UO}_{2}(\mathrm{OH})^{+}$, and $\mathrm{UO}_{2}(\mathrm{OH})_{3}{ }^{+}$species (25). Based on these evaluations, we kept the $\mathrm{pH}$ value at constant 4.1 (own value of $\mathrm{UO}_{2}{ }^{2+}$ solution). Below this value, we observed some distortions in the geometry of amidoximated copolymer, and even better $\mathrm{UO}_{2}{ }^{2+}$ adsorption values were obtained. Some hydroxyl species formed above this limit $\mathrm{pH}$ value. During the whole adsorption experiments, this $\mathrm{pH}$ value was not affected with the presence of neutral ethyl cellulose copolymers although very few fluctuations occurred within $\mathrm{pH}$ 4-4.5.

Figure 1 shows the decrease in $\mathrm{UO}_{2}{ }^{2+}$ concentrations in time for constant composition of EC- $g$ $\mathrm{AO}$ (the initial composition of $0.6 \mathrm{~g}$ EC in $6 \mathrm{~mL}$ acrylonitrile (AN) were used in our previous paper) copolymers for different initial $\mathrm{UO}_{2}{ }^{2+}$ concentrations at $25^{\circ} \mathrm{C}$ (at $\mathrm{pH} 4.1$ ). Using first order kinetic model, the initial rates $\left(-\mathrm{d}\left[\mathrm{UO}_{2}{ }^{2+}\right] / \mathrm{dt}=\mathrm{r}_{\mathrm{i}}\right)$, calculated based on the initial slope of those 
curves shown in Figure 1, are presented in Table 1, for each temperature, as a function of the initial $\mathrm{UO}_{2}{ }^{2+}$ concentration. Table 1 demonstrates that the $\mathbf{r i}_{\mathbf{i}}$ of interaction between $\mathrm{UO}_{2}{ }^{2+}$ and amidoxime groups increases with increasing concentration of $\mathrm{UO}_{2}{ }^{2+}$ at a given temperature. In addition, contrary to what we know about the physical and chemical adsorption, the $\mathrm{UO}_{2}{ }^{2+}$ adsorption increases with rising temperatures. This is because the structure of ethyl cellulose contains plenty of $\mathrm{OH}$ groups that link the glucose units layered. Rising temperature may cause some of these bonds to be broken and the rigidity of ethyl cellulose is decomposed to a certain extent. The adsorption rate of $\mathrm{UO}_{2}{ }^{2+}$ on copolymers increases, enabling access to amidoxime groups.

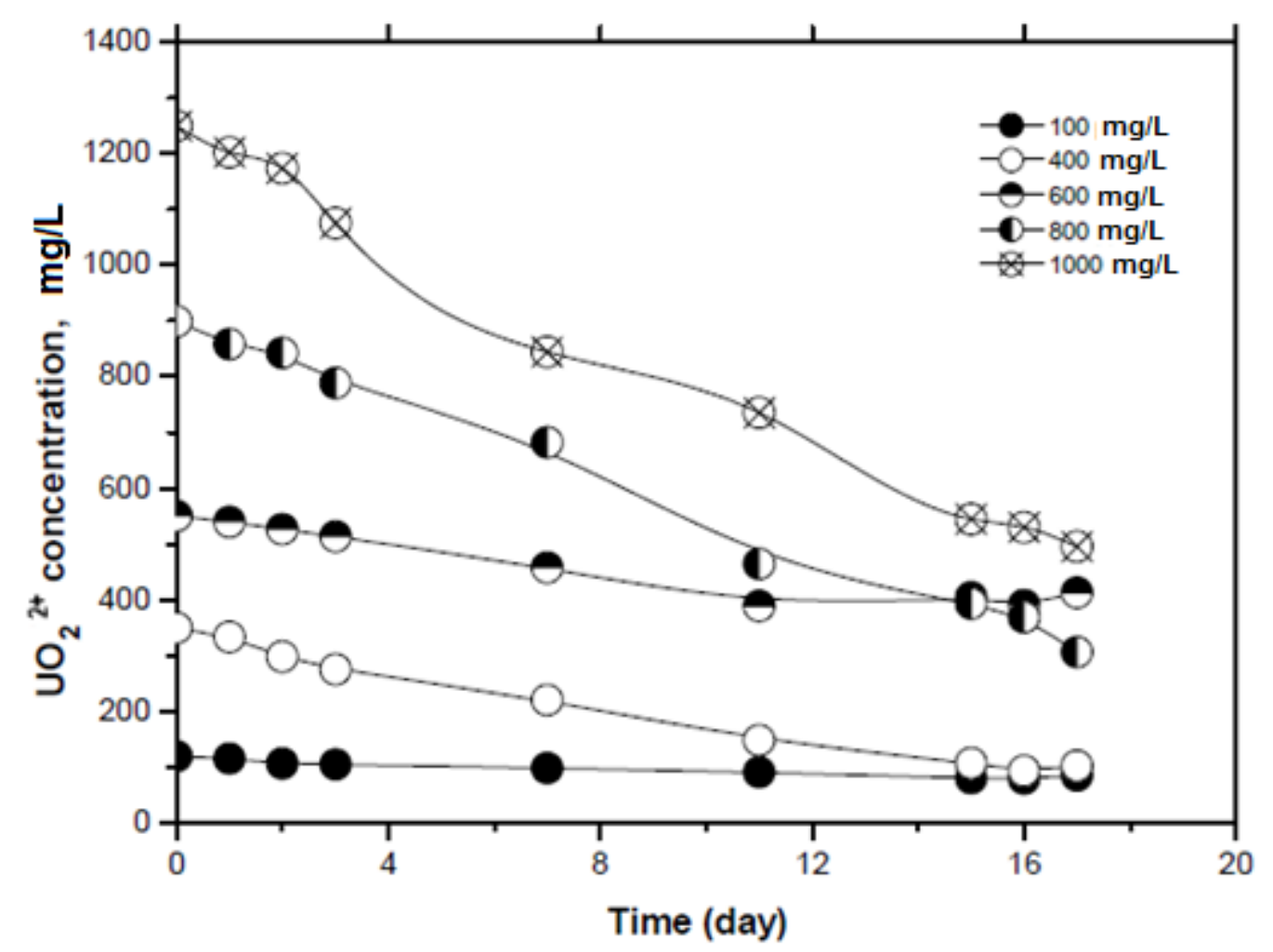

Figure 1. Kinetics of $\mathrm{UO}_{2}{ }^{2+}$ adsorption at different $\mathrm{UO}_{2}{ }^{2+}$ concentrations ( $0.6 \mathrm{~g} \mathrm{EC}$ dissolved in $6 \mathrm{~mL}$ of $\mathrm{AN} ; 25^{\circ} \mathrm{C} ; \mathrm{pH} 4.1$ ) 
Table 1. Initial rates and rate constants calculated from kinetic data.

\begin{tabular}{clllc}
\hline Temperature & $\begin{array}{l}\text { Initial conc. of } \\
\mathrm{UO}_{2}{ }^{2+}(\mathrm{mg} / \mathrm{L})\end{array}$ & $\begin{array}{l}\text { initial conc. of } \mathrm{UO}_{2}{ }^{2+} \\
\left(\times 10^{4} \mathrm{~mol} / \mathrm{L}\right)\end{array}$ & $\begin{array}{l}\text { Initial rate, } \mathrm{r}_{\mathrm{i}}\left(\mathrm{x} 10^{6}\right. \\
\mathrm{mol} / \mathrm{L} . \mathrm{h})\end{array}$ & $\begin{array}{l}\text { rate constant, } \mathrm{k} \\
\left(\times 10^{4} 1 / \mathrm{h}\right)\end{array}$ \\
\hline \multirow{3}{*}{$25^{\circ} \mathrm{C}$} & 400 & 14.80 & 2.34 & \\
& 600 & 22.22 & 3.76 & \\
& 800 & 29.62 & 4.43 & \\
& 1000 & 37.03 & 4.96 & \\
& 400 & 14.80 & 4.32 & \\
& 600 & 22.22 & 4.96 & \\
& 800 & 29.62 & 7.13 & \\
& 1000 & 37.03 & 8.63 & \\
& 400 & 14.80 & 4.87 & \\
& 600 & 22.22 & 6.39 & \\
& 800 & 29.62 & 8.24 & \\
\hline
\end{tabular}

Calculated $\mathbf{E}_{\mathbf{a}}$ value from Arrhenius equation $=\mathbf{4 3 . 0 4} \mathbf{~ k J} / \mathbf{m o l}$

Certain amounts of EC- $g$-AO copolymers were added to varying concentrations of $\mathrm{UO}_{2}{ }^{2+}$ solutions at known volume and shaken for a predetermined period (around 10 days). This process continued until the adsorption equilibrium was reached. The equilibrium amounts of adsorbed $\mathrm{UO}_{2}{ }^{2+}$ were calculated based on Equation 1 . The adsorption capacity values of $\mathrm{UO}_{2}{ }^{2+} \mathrm{mg} / \mathrm{g}$ dry copolymer were plotted versus equilibrium concentrations $\left(\mathbf{C}_{\mathbf{e}}\right)$ of $\mathrm{UO}_{2}{ }^{2+}$ to obtain adsorption isotherms for each temperature studied. From Figure 2, the adsorption isotherms demonstrate a high-affinity type (26) behavior due to the strong interaction between $\mathrm{UO}_{2}{ }^{2+}$ and amidoxime groups for all temperatures. The shape of the isotherms shows that the same amount of $\mathrm{UO}_{2}{ }^{2+}$ adsorption takes place in all active regions of EC- $g$-AO copolymers. In other words, adsorption takes place when the specifically adsorbed amount of ionic species on solid polymer exceeds that of ionic species found in the solution (27). To put it another way, copolymer gives a specific and strong significance to uranium; adsorption takes place very fast initially, then slows down as the sites available for adsorption decrease. This is the usual case for Langmuir isotherm. The linearized Langmuir equation (28) enables one to determine a significant parameter representing a measurement of the chelating resin-binding capacity for a given species [ $\mathbf{K}_{\mathbf{L}}$, the equilibriumbinding constant (Kads/ kdes)]. The linearized form of Langmuir equation is presented in Equation (6):

$$
\frac{C_{e}}{q_{e}}=\frac{1}{K_{L} q_{s}}+\frac{C_{e}}{q_{s}}
$$




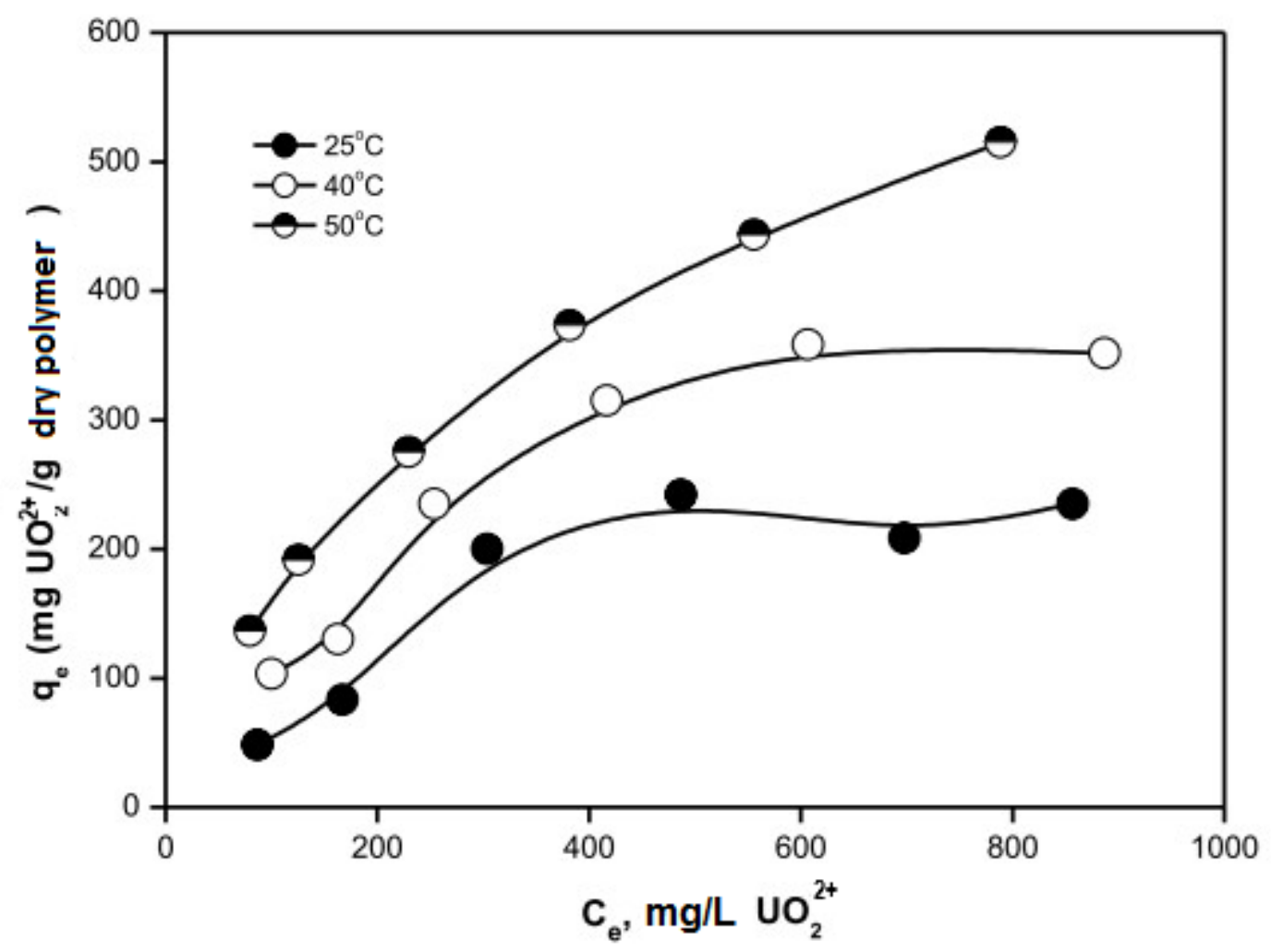

Figure 2. Adsorption isotherms obtained at different temperatures.

The $\mathbf{K}_{\mathbf{L}}$ values obtained for Ec- $g-A O$ copolymers are listed in Table 2 with $\mathbf{q}$ e values. Despite the fact that $\mathrm{UO}_{2}{ }^{2+}$ adsorption rose at higher temperatures, $\mathbf{K}_{\mathbf{L}}$ values indicated the genuine results: The desorption rate remained high at high temperatures for $\mathbf{K} \mathbf{L}$ values from 25 to $50^{\circ} \mathrm{C}$. Equations 2-4 and 6 are interpreted together in order to calculate the thermodynamic parameters of $\mathrm{UO}_{2}{ }^{2+}$ adsorption. Activation energy, entropy, enthalpy, and Gibbs free energy values applicable to the $\mathrm{UO}_{2}{ }^{2+}$ adsorption onto EC- $g$-AO copolymers were demonstrated in Tables 1 and 2 . Calculated from Equation 2, $\mathbf{E}_{\mathbf{a}}(43.04 \mathrm{~kJ} / \mathrm{mol})$ indicates that the adsorption of $\mathrm{UO}_{2}{ }^{2+}$ by $\mathrm{EC}-g-\mathrm{AO}$ copolymers has taken place through an internal diffusion-controlled process for chemical adsorption (30-120 kJ/mol) (29). Moreover, the other thermodynamic parameters calculated using Eq. 2-4 confirmed the powerful interaction between amidoxime groups and $\mathrm{UO}_{2}{ }^{2+}$, and such interactions have been demonstrated for exothermic favorability. In our study, the most important parameter that determines the tendency of a spontaneous event, Gibbs free energy, $\Delta \mathbf{G}_{\text {ads, }}$ has a negative value. In addition, $\Delta \mathrm{H}_{\text {ads }}$ value has been found as $-23.61 \mathrm{~kJ} / \mathrm{mol}$. This is very close to the threshold of the enthalpy of chemical adsorption and that of the physical adsorption. Adsorption happens physically at $\Delta \mathrm{H}_{\text {ads }}<<-40 \mathrm{~kJ} / \mathrm{mol}$ and chemically at $\Delta \mathrm{H}_{\text {ads }}>-$ $40 \mathrm{~kJ} / \mathrm{mol}$. Although the interaction between $\mathrm{UO}_{2}{ }^{2+}$ and amidoxime groups takes place with the aim of physical forces, binding between the two is quite strong. Desorption studies support our findings in this context. 
Table 2. Thermodynamic parameters of $\mathrm{UO}_{2}{ }^{2+}$ adsorption onto EC-g-AO copolymers

\begin{tabular}{lllll}
\hline Temperature & $\mathbf{q}_{\mathbf{e}}$ & $\mathbf{K}_{\mathbf{L}}$ (Langmuir & $\mathbf{- \Delta \mathbf { G } _ { \text { ads } } ( \mathbf { k J } / \mathbf { m o l } ,}$ & $\begin{array}{l}\Delta \mathbf{S}_{\text {ads }}(\mathbf{J} / \mathbf{K} \text { mol, Gibbs- } \\
\text { Helmholtz eqn. ) }\end{array}$ \\
\hline $\left.\mathbf{(}{ }^{\circ} \mathbf{C}\right)$ & $\mathbf{( m g / g )}$ & $\mathbf{e q n})$. & Gibbs eqn. ) & 27.18 \\
40 & 24 & 523 & 15.51 & 30.48 \\
50 & 35 & 292 & 14.07 & 30.60 \\
\hline
\end{tabular}

$\Delta \mathbf{H}_{\text {ads }}=\mathbf{- 2 3 . 6 1} \mathbf{~ k J} / \mathbf{m o l}$ (Gibbs-Helmholtz eqn.)

The relevant literature $(12-14,30,31)$ contains many studies conducted on both amidoximated resin and unmodified biomass, separately, for the uranium recovery. But none of them included the uranium recovery by amidoximated biomass. In some studies, the modification was achieved by some acid groups (13), and in others, those heavy metal ions other than uranium (10) were used, or they presented only the synthesis and characterization. Therefore, direct study was not present for the uranium recovery by amidoximated cellulose. Only in one study performed by Badawy et al. (7) the authors showed that acrylonitrile/methacrylic acid grafted cotton cloths can be used to recover uranium from aqueous systems with an adsorption capacity of $662 \mu \mathrm{g} / \mathrm{g}$. This value is a rather small value from the value obtained in our study $(240 \mathrm{mg} / \mathrm{g})$.

To be able to explain the mechanism by which $\mathrm{UO}_{2}{ }^{2+}$ binds to amidoxime groups, FTIR/ATR spectra of $\mathrm{UO}_{2}{ }^{2+}$ adsorbed $\mathrm{EC}-\mathrm{g}$-AO copolymers were obtained, which are shown in Figure 3. Because of interactions with $\mathrm{UO}_{2}{ }^{2+}$, there are some shifts on some characteristic bands. The band for $\mathrm{C}=\mathrm{N}$ belonging to amidoxime group at $1660 \mathrm{~cm}^{-1}$ shifts by approximately $15 \mathrm{~cm}^{-1}$, and also there is an $8 \mathrm{~cm}^{-1}$ shift for $\mathrm{N}-\mathrm{O}$ stretching vibrations at $912 \mathrm{~cm}^{-1}$. The band intensity at 1550 $\mathrm{cm}^{-1}$, attributed to $\mathrm{C}-\mathrm{N}$ group of amidoxime, increased, and it got clearer after $\mathrm{UO}_{2}{ }^{2+}$ adsorption. Other band shifts occur at $3200 \mathrm{~cm}^{-1}$ for the interaction of both $=\mathrm{N}-\mathrm{OH}$ and $-\mathrm{NH}_{2}$ (of amidoxime) groups with $\mathrm{UO}_{2}{ }^{2+}$. This suggests that $\mathrm{UO}_{2}{ }^{2+}$ on $\mathrm{EC}-\mathrm{g}-\mathrm{AO}$ copolymers is absorbed through both $-\mathrm{C}-\mathrm{NH}_{2}$ and $-\mathrm{C}=\mathrm{N}-\mathrm{O}-\mathrm{H}$ segments of amidoxime, and the mechanism is proposed as in scheme 1: 


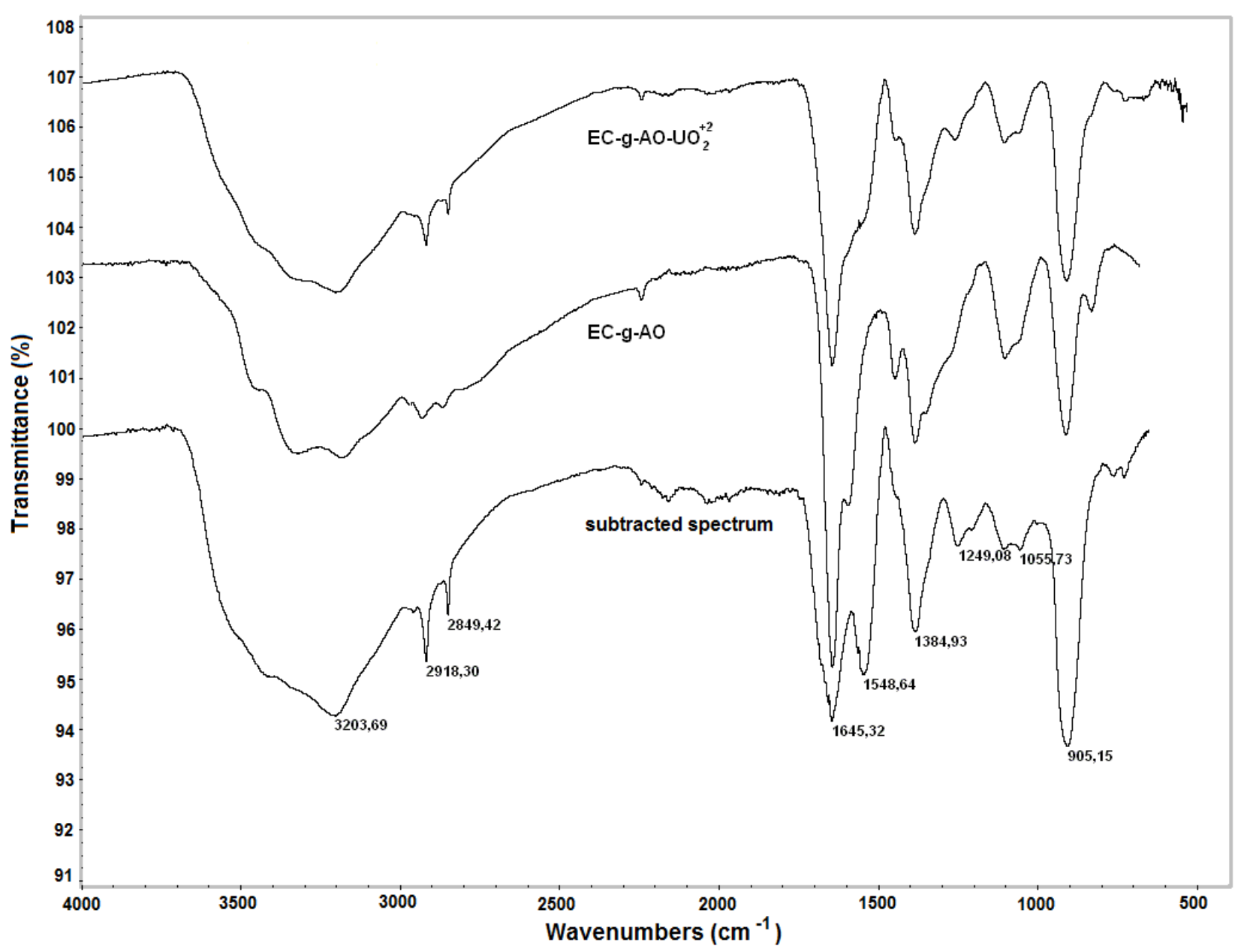

Figure 3. FTIR/ATR spectra of EC- $g$-AO copolymers before and after $\mathrm{UO}_{2}{ }^{2+}$ adsorption

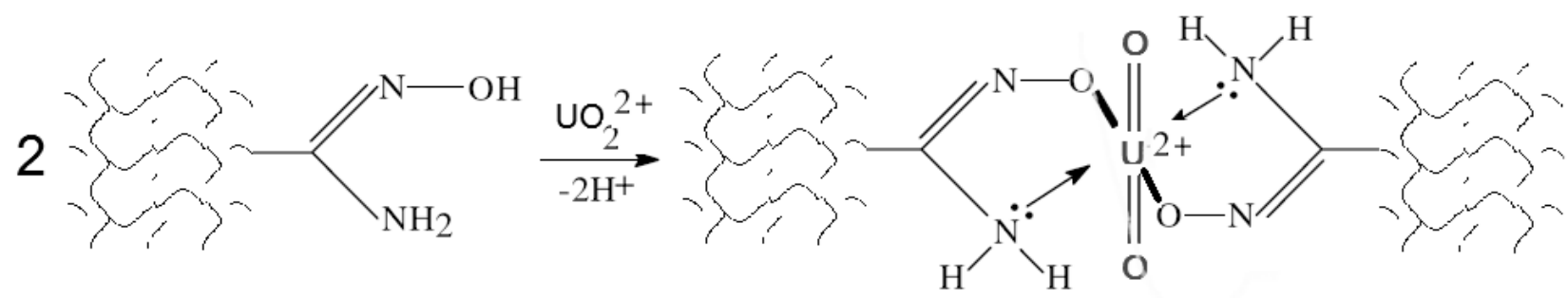

Scheme 1. Coordination of amidoxime group to uranyl cation.

Another similar mechanism was observed as part of the study of adsorption of metal ions by amidoxime-modified synthetic resins (32). Given the bidentate character of amidoxime groups, two amidoxime groups hold an $\mathrm{UO}_{2}{ }^{2+}$ as a clamp and ensure 6-coordination.

Thermal analyses were performed to account for the thermal behavior of EC- $g$-AO after $\mathrm{UO}_{2}{ }^{2+}$ adsorption. Evaluations of EC-g-AN copolymers in terms of TGA and derivative TGA before and after amidoxime conversion were reported in another study of ours (24). Figure 4 presents TGA, 
der.TGA, and DTA thermograms for $\mathrm{UO}_{2}{ }^{2+}$ adsorbed EC-g-AO copolymer. As can be seen in the figure, there are different steps of decomposition upon the adsorption of $\mathrm{UO}_{2}{ }^{2+}$. Due to the interaction between the amidoxime group and $\mathrm{UO}_{2}{ }^{2+}$, the level of decomposition observed at 275 ${ }^{\circ} \mathrm{C}$ corresponded to the amidoxime groups and the decomposition at $433^{\circ} \mathrm{C}$ corresponded to cellulosic structures. The addition of $\mathrm{C} \equiv \mathrm{N}$ (nitrile) groups affected it, leading a slight increase in the cellulose's stability. The decompositions observed at $462^{\circ} \mathrm{C}, 508^{\circ} \mathrm{C}$ and $621^{\circ} \mathrm{C}$ probably show the decompositions of some groups which interacted with $\mathrm{UO}_{2}{ }^{2+}$. The last three decompositions were not observed in the TGA thermogram of EC-g-AO copolymer itself (24). The EC-g-AO copolymer lost approximately $90 \%$ of its weight throughout the heating process that continued up to $700^{\circ} \mathrm{C}$. Since the $\mathrm{UO}_{2}{ }^{2+}$ did not diffuse thoroughly into the crystalline cellulose by defeating strong $\mathrm{H}$-bonds, it would not access to all adsorption sites, and the adsorption amounts of $\mathrm{UO}_{2}{ }^{2+}$ is lesser compared to the other studies in the literature (33-35). As a result, such a high weight loss arose from carbonization of cellulosic units. When the residue of TGA was analyzed, it was shown that the structure belongs to $\mathrm{U}_{3} \mathrm{O}_{8}(36)$.

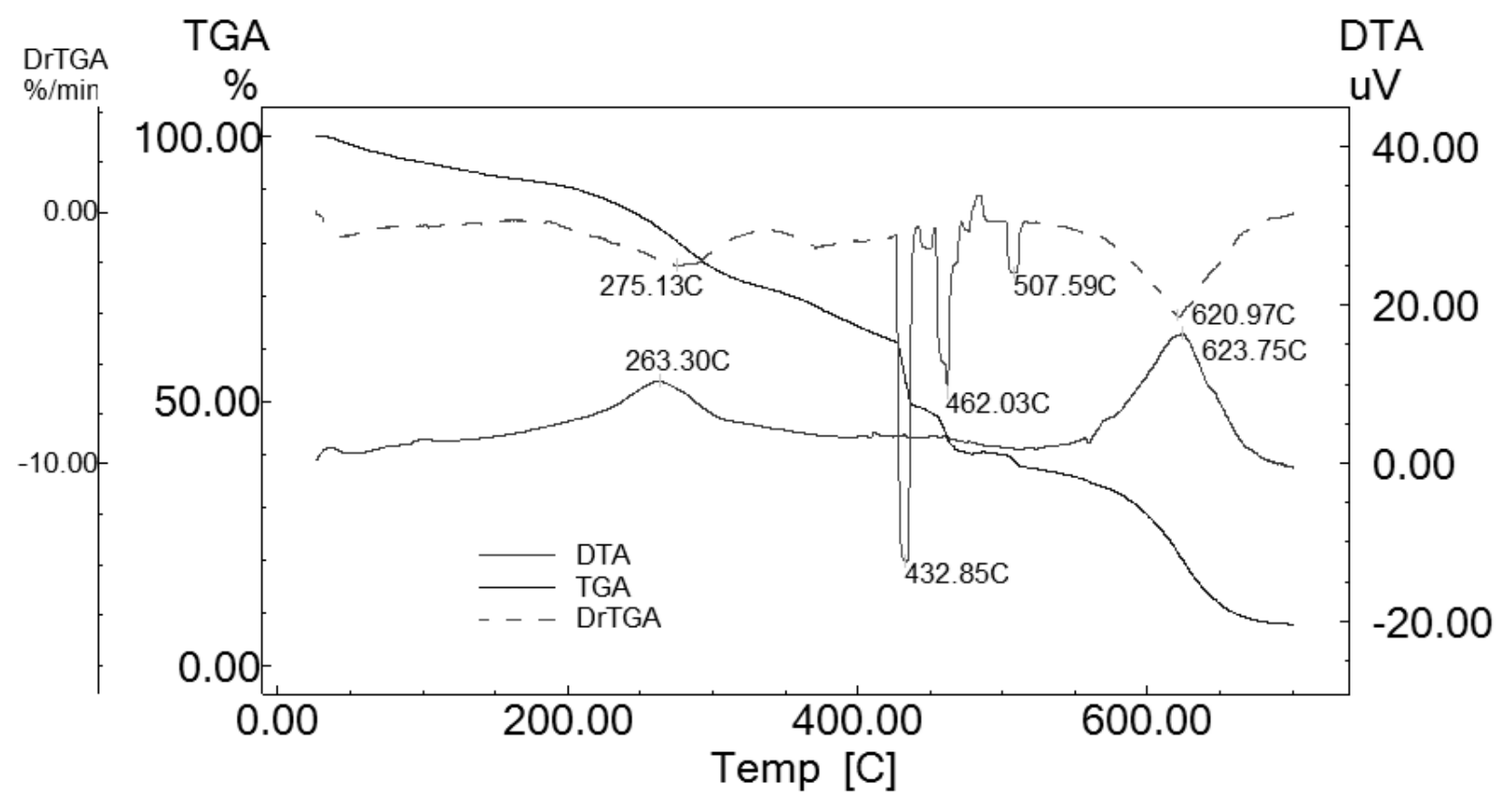

Figure 4. TGA thermogram of EC- $g$-AO copolymers after $\mathrm{UO}_{2}{ }^{2+}$ adsorption.

SEM and SEM-EDX images were obtained to analyze the surface morphology of EC- $g$-AO copolymers following $\mathrm{UO}_{2}{ }^{2+}$ adsorption. The Scanning Electron Microscopy (SEM) enables an observation of the materials' topographic features as 3-D images, whereas the Energy Dispersive X-Ray Spectroscopy (EDX) allows performance of an elemental analysis on the materials' microscopic sections. The SEM images of EC- $g$-AO copolymers, before and after $\mathrm{UO}_{2}{ }^{2+}$ adsorption, are provided in Figure 5 . As shown in the figure $(b, c)$, there are highly visible orthorhombic bipyramidal crystal structures of $\mathrm{UO}_{2}{ }^{2+}$. In the colored figure, bright regions observed around crystals indicates that radioactive heavy metal ion is attached to the structure. 
SEM images were taken to analyze if the $\mathrm{UO}_{2}{ }^{2+}$ is connected to $\mathrm{EC}-\mathrm{g}$-AN copolymer before amidoxime conversion (Figure 5(a)). As can be clearly seen, the absence of $\mathrm{UO}_{2}{ }^{2+}$ crystals on the topological image of EC-g-AN copolymer confirmed that the unamidoximated copolymer did not adsorb $\mathrm{UO}_{2}{ }^{2+}$. This draws attention to similar crystal occurrences on the surface, reported by Allen and Tempest (37). The orthorhombic bipyramidal crystal structure of $\mathrm{UO}_{2}{ }^{2+}$, which is seen on the copolymer surface, is presented in Scheme 2:

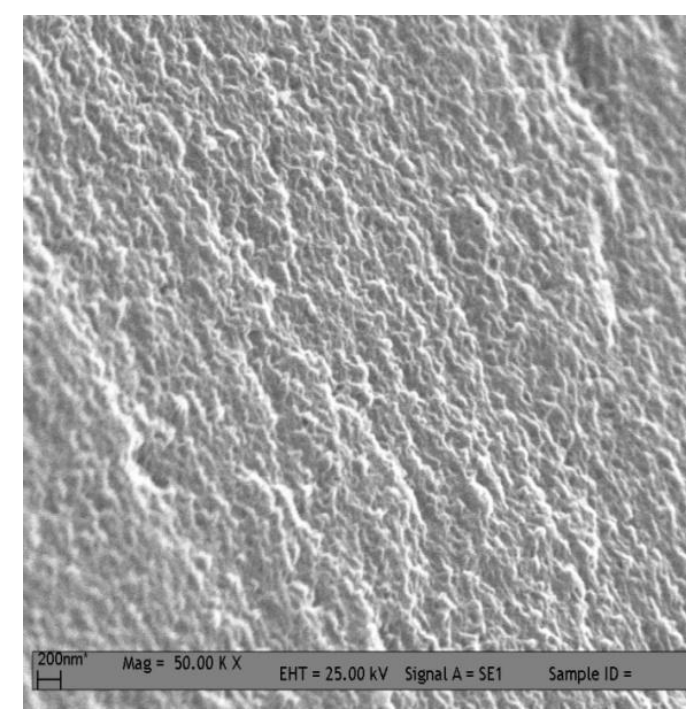

(a)

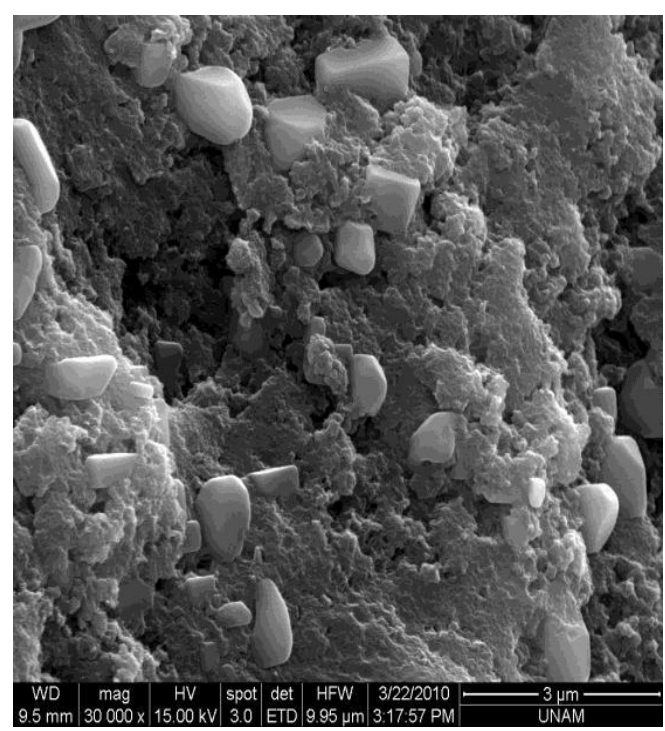

(b)

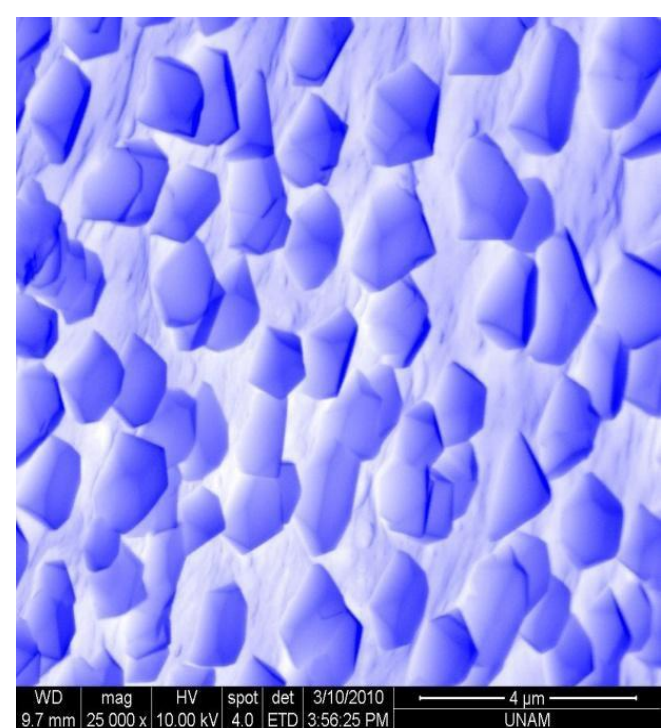

(c)

Figure 5. SEM images of (a) EC-g-AN- $-\mathrm{UO}_{2}{ }^{2+}$, (b), and (c) EC-g-AO-UO ${ }_{2}{ }^{2+}$ systems 

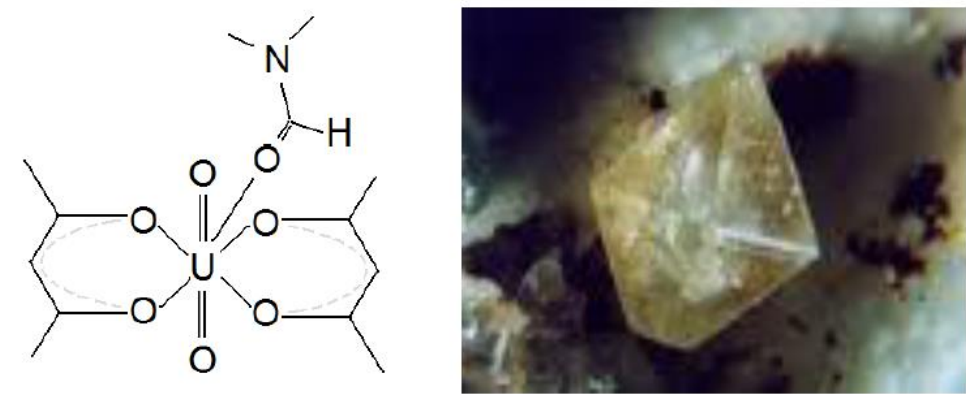

Scheme 2. The orthorhombic bipyramidal crystal structure of $\mathrm{UO}_{2}^{2+}$.

Using EDX as a non-destructive determination method, it is possible to perform a quantitative analysis of uranium in the organic or inorganic compounds. To this aim, EDX spectrum of $\mathrm{UO}_{2}{ }^{2+}$ adsorbed EC-g-AO was taken simultaneously based on the SEM image. The surface was coated with gold $(\mathrm{Au})$ for conductivity during the analysis. As indicated in Figure 6, the $\mathrm{UO}_{2}{ }^{2+}$ attached sites are marked in red, and the copolymer surface is almost entirely covered by $\mathrm{UO}_{2}{ }^{2+}$. Starting from the low energy region, the bands observed for $0.4 \mathrm{keV}$ and $0.5 \mathrm{keV}$ were attributed to $\mathrm{N}$ $\mathrm{K}_{\alpha}$, and $\mathrm{O} \mathrm{K}_{\alpha} \mathrm{X}$-ray lines, respectively. Due to the copolymer surface coated with $\mathrm{Au}$, bands observed at $2.120 \mathrm{keV}$, and $9.712 \mathrm{keV}$ belong to $A u M_{\alpha}$, and $A u L_{\alpha} X$-ray lines, respectively. The EDX spectrum revealed two different lines depending on $\mathrm{UO}_{2}{ }^{2+}$ adsorption: one is at $3.17 \mathrm{keV}$, which corresponds to $U M_{\alpha}$, and the other is at $3.34 \mathrm{keV}$, belonging to $U M_{\beta}$. It is normal that the band intensities corresponding to the energy values are different because the $\mathrm{UO}_{2}{ }^{2+}$ adsorption values obtained at different initial concentrations are different.

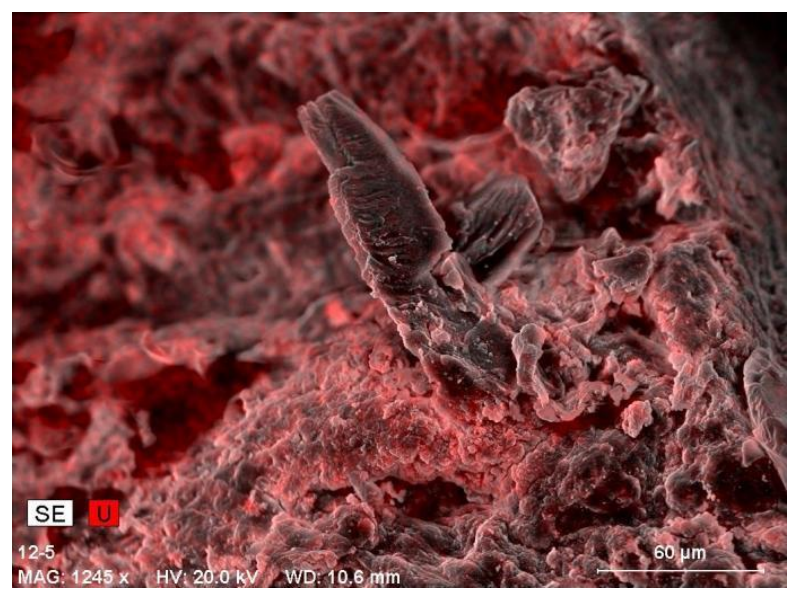




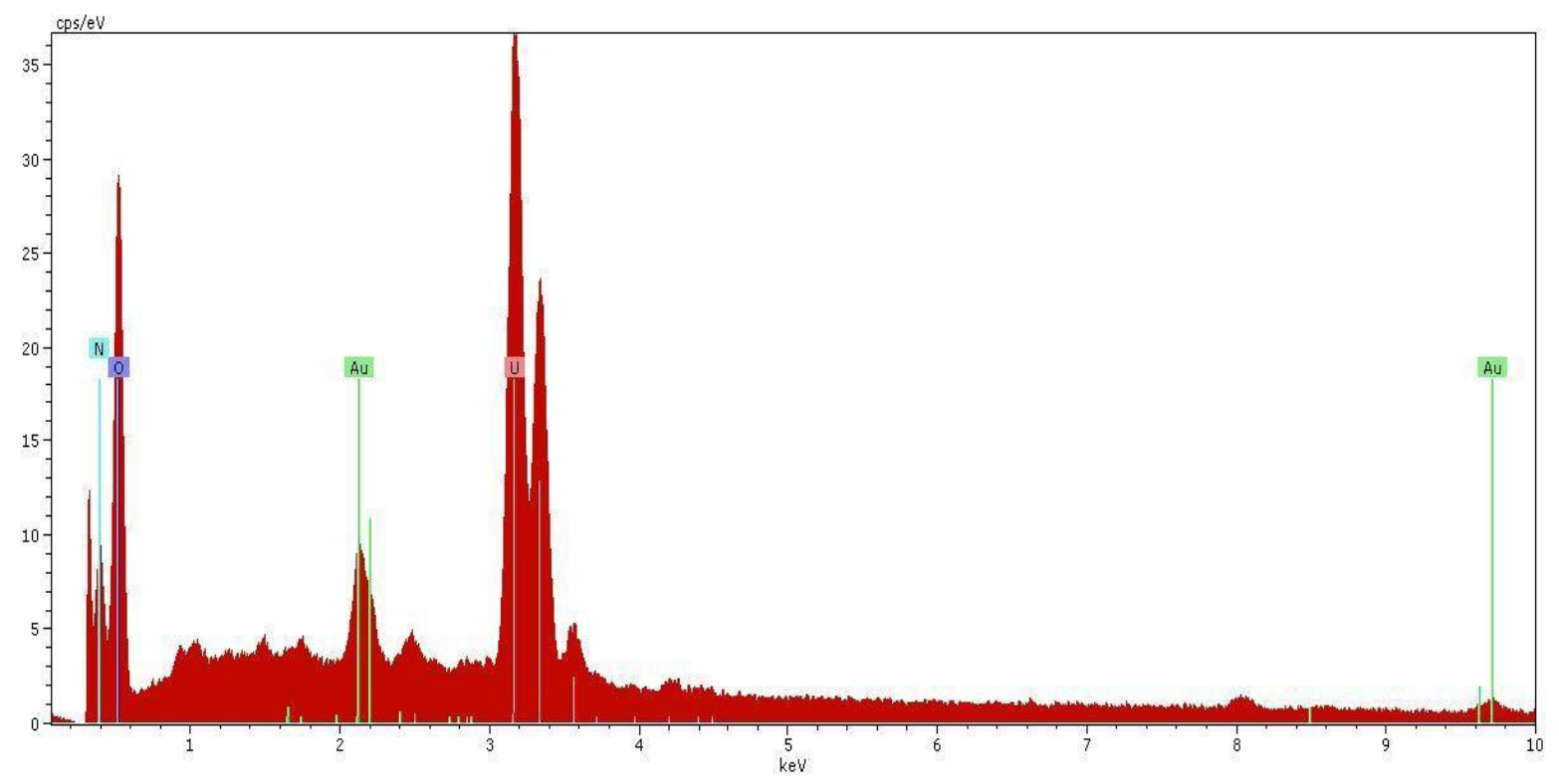

Figure 6. SEM-EDX spectrum of $\mathrm{UO}_{2}{ }^{2+}$ adsorbed EC- $g$-AO copolymer (adsorption conditions: $800 \mathrm{mg} / \mathrm{L} \mathrm{UO}_{2}{ }^{2+}, 25^{\circ} \mathrm{C}, \mathrm{pH} 4.1$ )

The final part of our study featured desorption experiments to determine the release of $\mathrm{UO}_{2}{ }^{2+}$ from EC- $g$-AO copolymers. Certain amounts of $\mathrm{UO}_{2}{ }^{2+}$ adsorbed $\mathrm{EC}-\mathrm{g}$-AO copolymers were separately added to $10 \mathrm{~mL}$ of EDTA, $\mathrm{HCl}, \mathrm{NaOH}$, and $\mathrm{NaHCO}_{3}$ solutions ( $0.1 \mathrm{M}$ each), and we measured, in regular intervals, the concentration of released $\mathrm{UO}_{2}{ }^{2+}$ with UV-Vis spectrophotometer at $429 \mathrm{~nm}$. The values of desorption (\%) were calculated based on Equation 5. Table 3 indicates the total amounts of $\mathrm{UO}_{2}{ }^{2+}(\%)$ released from different desorption agent solutions. As can be seen in the table, $\mathrm{NaHCO}_{3}$ is the most effective agent for desorption. Desorption of $\mathrm{UO}_{2}{ }^{2+}$ from $\mathrm{EC}-\mathrm{g}-\mathrm{AO}$ copolymer in $0.1 \mathrm{M} \mathrm{NaHCO}_{3}$ was found to be $52 \%$. A similar result was observed in the study conducted by Das et al. (13). In their study, amidoximated electron-beam-grafted polypropylene membranes were used for the uranium recovery; desorption of uranium from membrane was realized with $1.0 \mathrm{M} \mathrm{NaHCO}_{3}$ with $85 \%$ yield. Table 3 reveals another interesting point: We found that the desorption yield remained only at $52 \%$. In our view, the low desorption yield might be due to the strong interaction between amidoxime groups close to the chemical adsorption boundary.

Table 3. Total release amounts (\%) of $\mathrm{UO}_{2}{ }^{2+}$ from EC- $g$-AO copolymers using different desorption agents.

\begin{tabular}{lccccc}
\hline \multirow{2}{*}{$\mathrm{mg} \mathrm{UO}_{2}{ }^{2+} / \mathrm{g}$ copolymer } & \multicolumn{4}{c}{ Total UO $_{2}{ }^{2+}$ release (\%) } \\
\cline { 3 - 6 } & $0.1 \mathrm{M} \mathrm{HCl}$ & $0.1 . \mathrm{M} \mathrm{EDTA}$ & $0.1 \mathrm{M} \mathrm{NaHCO}_{3}$ & $0.1 \mathrm{M} \mathrm{NaOH}$ \\
240 & 17 & 12 & 52 & 13 \\
\hline
\end{tabular}

\section{CONCLUSIONS}

The EC- $g$-AO copolymers are prepared by gamma irradiating binary mixtures of ethyl cellulose and acrylonitrile and subsequent amidoximation of the grafting chains. The adsorption behavior 
of the uranyl ions in initial concentrations over a range of $100-1000 \mathrm{mg} / \mathrm{L}$ on the EC-g-AO copolymers is studied by the batch technique at a $\mathrm{pH}$ value of 4.1 at different temperatures. Interaction between $\mathrm{UO}_{2}{ }^{2+}$ and amidoxime groups increases with increasing concentration of $\mathrm{UO}_{2}{ }^{2+}$ at a given temperature. It can be found that the temperature induces a positive effect on the adsorption process and the adsorption capacity increases with an increase of $\mathrm{UO}_{2}{ }^{2+}$ initial concentration. The findings suggested an adsorption capacity of $240 \mathrm{mg} \mathrm{UO}_{2}{ }^{2+} / \mathrm{g}$ dry copolymer. Desorption of adsorbed $\mathrm{UO}_{2}{ }^{2+}$ ions from EC- $g$-AO copolymers was performed using different agents and it was found that $\mathrm{NaHCO}_{3}$ is the most effective agent for desorption.

\section{ACKNOWLEDGMENTS}

This study was conducted as part of the Chemistry Department, Hacettepe University. The authors gratefully acknowledge the support provided by the HU Scientific Research Foundation through the project no. HU-BAB-010D08601006.

\section{REFERENCES}

1. David Talbot: Uranium and lithium demand powers stocks. Available at http://www.theenergyreport.com/pub/na/10323.

2. Egawa H, Kabay N, Jyo A, Hirono M, Shuto T. Recovery of uranium from seawater.15. Development of amidoxime resins with high sedimentation velocity for passively driver fluidized bed adsorbers. Ind Eng Chem Res. 1994; 33:657-61.

3. Atia AA, Donia AM, Abou-El-Enein SA, Yousif AM. Studies on uptake behaviour of copper(II) and lead(II) by amine chelating resins with different textural properties. 2003; Sep Purif Technol. 33:295-301.

4. Nilchi A, Babalou AA, Rafiee R, Sid Kalal $H$. Adsorption properties of amidoxime resins for separation of metal ions from aqueous systems. Reac Func Polym. 2008; 68:1665-70.

5. Liu X, Chen H, Wang C, Qu R et al. Adsorption properties of amidoximated porous acrylonitrile/methyl acrylate copolymer beads for Ag (I). Polym Adv Technol. 2011; 22:2032-8.

6. Tagami K, Uchida S. Use of TEVA resin for the determination of $U$ isotopes in water samples by Q-ICPMS. Appl Radiat Isotopes. 2004; 61:255-9.

7. Badawy SM, Sokker HH, Othman SH, Hashem A. Cloth filter for recovery of uranium from radioactive waste. Radiat Phys Chem. 2005; 73:125-130.

8. D'Souzaa SF, Sarb P, Kazyc SK, Kubala BS. Uranium sorption by Pseudomonas biomass immobilized in radiation polymerized polyacrylamide bio-beads. J Environ Sci Health, Part A. 2006; 41:487-500.

9. Chauhan GS, Kumar A. A study in the uranyl ions uptake on acrylic acid and acrylamide copolymeric hydrogels. J Appl Polym Sci. 2008; 110:3795-803.

10. O'Connell DW, Birkinshaw C, Dwyer TF. Heavy metal adsorbents prepared from the modification of cellulose: A review. Biores Technol. 2008; 99:6709-24.

11. Egawa $\mathrm{H}$, Harada $\mathrm{H}$. Recovery of uranium from seawater by using chelating resins containing amidoxime groups. Nippon Kagaku Kaishi. 1979; 958-9.

12. Rivas BL, Maturana HA, Villegas S. Adsorption behavior of metal ions by amidoxime chelating resin. J Appl Polym Sci. 2000; 77:1994-9. 
13. Choi $\mathrm{SH}$, Nho YC. Adsorption of $\mathrm{UO}_{2}^{+2}$ by polyethylene adsorbents with amidoxime, carboxyl, and amidoxime/carboxyl group. Radiat Phys Chem. 2000; 57:187-93.

14. Das S, Pandey AK, Athawale A, Kumar V, Bhardwaj YK, Sabharwal S, Manchanda VK. Chemical aspects of uranium recovery from seawater by amidoximated electron-beam-grafted polypropylene membranes. Desalination. 2008; 232:243-53.

15. Neti VS, Das S, Brown S, Janke CJ, Kuo L, Gill GA, Dai S, Mayes RT. Efficient functionalization of polyethylene fibers for the uranium extraction from seawater through atom transfer radical polymerization. Ind Eng Chem Res. 2017; 56:10826-32.

16. Abney CW. Mayes RT, Saito T, Dai S. Materials for the recovery of uranium from seawater. Chem Rev. 2017; 117:13935-14013.

17. Amphlett JTM, Ogden MD, Foster RI, Syna N, Soldenhoff K, Sharrad CA. Polyamine functionalisedion exchange resins: Synthesis, characterization and uranyl uptake. Chem Eng J. 2018; 334:1361-70.

18. Chau H, Yu P. Production of biodegradable plastics from chemical wastewater - A novel method to resolve excess activated sludge generates from industrial wastewater treatment. Water Sci Technol. $1999 ; 39: 273-80$.

19. Gupta KC and Sahoo S. Graft copolymerization of acrylonitrile and ethyl methacrylate comonomers on cellulose using ceric ions. Biomacromol. 2001; 2:239-47.

20. Gurgel LVA, Karnitz Jr O, de Freitas Gil RP, Gil LF. Adsorption of $\mathrm{Cu}$ (II), Cd(II), and Pb(II) from aqueous single metal solutions by cellulose and mercerized cellulose chemically modified with succinic anhydride. Biores Technol. 2008; 99:3077-83.

21. Akhtar K, Khalid AM, Akhtar MW, Ghauri MA. Removal and recovery of uranium from aqueous solutions by Ca-alginate immobilized Trichoderma harzianum. Biores Technol. 2009; 100:4551-8.

22. Zhou D, Zhang L, Zhou J, Guo S. Cellulose/chitin beads for adsorption of heavy metals in aqueous solution. Water Res. 2004; 38:2643-50.

23. Wang L, Dong W, Xu Y. Synthesis and characterization of hydroxy propylmethyl cellulose and ethyl acrylate graft copolymers. Carbohyd Polym. 2007; 68:626-36.

24. Başarır SŞ and Bayramgil NP. The uranium recovery from aqueous solutions using amidoxime modified cellulose derivatives. I. Preparation, characterization and amidoxime conversion of radiation grafted ethyl cellulose-acrylonitrile copolymers. Radiochim Acta. 2012; 100:893-9.

25. Qadeer R, Hanif J, Saleem M, Afzal M. Effect of alkali metals, alkaline earth metals and lanthanides on the adsorption of uranium on activated charcoal from aqueous solutions. J Radioanal Nucl Chem. $1992 ; 165: 243-53$.

26. Giles CH, MacEwan TH, Nakhwa SN, Smith D. Studies in adsorption. Part XI. A system of classification of solution adsorption isotherms, and its use in diagnosis of adsorption mechanisms and in measurements of specific surface areas of solids. J Chem Soc. 1960; 10:3973-93.

27. IUPAC Compendium Chem Terminology (1986) IUPAC. 58:448.

28. Bolster $\mathrm{CH}$, Hornberger GM. On the use of linearized Langmuir equations. Soil Sci Soc Am J. 2007; 71:1796-1806, http://agris.fao.org/agris-search/search.do?recordID= US201300814267.

29. Saeed MM, Rusheed A, Ahmed N. Kinetics and thermodynamic aspect of the adsorption of Fe (III) on HTTA-imbedded polyurethane foam. J Radioanal Nucl Chem. 1996; 211:293-303.

30. Cou WH, Chao L, Zhu L. Efficient uranium(VI) biosorption on grapefruit peel: Kinetic study and thermodynamic parameters. J Radioanal Nucl Chem. 2012; 292:1303-15.

31. Li F, Tang Y, Wang HL, Yang JJ, Li SJ, Liu J, Tu H, Liao JL, Yang YY, Liu N. Functionalized hydrothermal carbon derived from waste pomelo peel as solid-phase extractant for the removal of uranyl from aqueous solution. Environmental Sci Poll Res. 2017; 24:22321-31. 
32. Zohuriaan-Mehr MJ. Advances in chitin and chitosan modification through graft copolymerization: A comprehensive review. Iran Polym J. 2005; 14:235-65.

33. Nakajima A, Horikoshi T and Sakaguchi T. Recovery of uranium by immobilized microorganisms. Eur J Appl Microbiol Biotechnol. 1982; 16:88-91.

34. Gerente $C$, Andres $Y$ and Le Cloirec $P$. Uranium removal onto chitosan: Competition with organic substances. Environ Technol. 1999; 20:515-21.

35. Na C, Park H, Kim B. Optimal amidoximation conditions of acrylonitrile grafted onto polypropylene by photoirradiation-induced graft polymerization. J Appl Polym Chem. 2012; 125:776-85.

36. Nyquist RA, Kagel RO. Infrared Spectra of Inorganic Compounds. Academic: New York, 1971 ; p 232.

37. Allen GC, Tempest PA. Ordered defects in the oxides of uranium. Proceedings of the Royal Society of London Series A. 1986; 406:325-44. 
